\title{
Cross Country Tax Competition and its Impact on Multinational Corporations -a Theoretical Re-examination
}

\author{
Sovik Mukherjee
}

Assistant Professor in Economics, Department of Commerce (Evening), Shri Shikshayatan College, West Bengal, India.

\begin{abstract}
The recent wave of globalization has made the global corporations to take advantage of the international tax differences and suitably shift their profits from low tax to high tax jurisdictions. In this paper, we consider a simple world with two countries with different market sizes and $n$ multinationals having a branch in each country. For simplicity, we have considered that both the countries impose a source-based tax on profit of the multinational firms. Moreover, these firms function in a Cournot framework with tax competition between the countries and shift their profit depending on the extent of tax differential. But profit shifting is costly as there is a chance of getting caught. In this backdrop, we propose a simple theoretical model which puts emphasis on the role of concealment of true profits in a framework of tax competition. It is shown that given the similar administrative efficiency across the countries, a higher probability of non-detection indicates that more profits will be declared in the lower tax country. Also, a fall in non-detection probability will reduce the tax revenue but there is a possibility that it might raise the overall revenue collections of the government. So, the focus should not only be on tax revenue per se but on other forms of revenue collections also.
\end{abstract}

Key words: Global Corporations, Concealment costs, Profit shifting, Tax Competition. JEL Classification: H26, H73, H77, H87.

(C) The Author, 2018. This article is published with open access at Sumy State University.

\section{Introduction}

The recent wave of globalization has made the global corporations to exploit the international tax differences and accordingly shift their profits from low tax to high tax jurisdictions. We propose some solutions that are applicable to all jurisdictions with different tax rates and market sizes. To start with, it is common knowledge that there exists a fiscal externality when several countries share a movable tax base, i.e. the tax rate set by one country has an impact on the tax base of the other country and may lead to inefficient outcomes deviating from the optimum. The literature has identified this fiscal externality and policy prescriptions to control its negative effects have become a major concern (Hindriks et al., 2014). The fact that multinationals use their various affiliates as an instrument to shift profits across countries is well recognized. Countries compete in source based taxes and multinational firms shift profits from the high to the low tax country at some cost. The concept of cost that is being talked about is defined as concealment cost and there exists a rich literature in this regard (Haufler \& Schjelderup, 2000; Kind et al., 2003, Riedel \& Runkel, 2006; Schindler \& Schjelderup, 2013). The global corporations use the tax differentials to trim down their tax liability coupled with the problem that these tax rates are chosen in a non-cooperative manner by different governments simultaneously. In this respect, Raimondos-Møller and Scharf (2002), Mansori and Weichenrieder (2001) try to give shape to transfer pricing rules put in place by two competing governments and investigate how such tax competition affects the equilibrium tax rates. In spite of the increasing importance of multinational firms streamlining their financial flows across provinces (Refer to OECD's website for details on BEPS ${ }^{1}$ ), the study of corrective measures in a framework where countries compete for profits of multinationals has not been analyzed thus far. In this context, will imposing strict rules with regard to profit shifting be beneficial for countries with heterogeneous features. Does the presence of stringent rules affect the revenue collections of the governments adversely? Also, how will a change in the rules relating to profit shifting influence the magnitude of profit a multinational firm declares. This paper has taken a modest attempt in resolving these fusillade of questions that have motivated this topic.

\footnotetext{
${ }^{1}$ Base erosion and profit shifting (BEPS) refers to tax avoidance tactics that exploit gaps and loopholes in tax rules.
} 
The rest of the paper is organized as follows. A select literature on issues relating to the taxation of MNCs has been reviewed in Section b. In Section c, we characterize the model, followed by discussing the results of the model in Section d. Finally, the paper ends with a conclusion.

\section{Review of Select Literature}

The literature on tax competition literature has developed significantly in the recent years with the countries competing for the mobile capital base and the inability of the countries to agree on measures of tax coordination. The motivation for this topic comes from the scenario where the corporate tax rates across EU member countries got affected in an endeavour to do a 'race to the bottom' (Haufler and Lülfesmann, 2015). The second issue is related to the form of competition of attracting capital and investments in a particular jurisdiction. According to Hindriks et al. (2014), "when several national fiscal authorities share a mobile tax base, one country's tax rate changes the tax base of the other, thereby creating a fiscal externality which leads to sub-optimal outcomes." Peralta and van Ypersele (2006) proposed policies like full tax harmonization, tax floors and ranges, government's matching grants to tackle this externality. Their argument was that with such policy instruments in place there will be less competitive pressures and to a certain extent one can control this "race to the bottom" phenomenon between jurisdictions. In a different setting, Baldwin and Krugman (2004) have found that tax revenue as a percent of GDP differs largely between the so-called "core" i.e. developed and "periphery" i.e. the developing countries. Their theoretical model justifies that firms in the developed (core) countries are more likely to pay higher taxes in return for better infrastructure and proximity to a larger market. In a similar setting, Vandenbussche et al. (2005) using firm level effective tax rates for large Belgian firms, find large regional disparities, where the "peripheral" region of Wallonia charges a much lower effective tax rate than the "core" region of Flanders.

Moving away from the impact on the profit levels of MNCs, there is a growing body of literature which talks about cross country tax competition and other related issues in this context. A brief discussion on other issues related to cross country tax competition follows. Fumagalli's (2003) work looks into tax competition between two countries that host one local firm but differ in terms of technology levels and compete to attract the manufacturing plant of a producer from a third country. Haufler and Wooton (1999) bring in the population dimension to discuss the case of tax competition between two countries having different sizes (in terms of population). They show that the MNCs will have an incentive to locate in the larger country given a very small amount of subsidy provision. Besley and Seabright (1999) introduced competition for foreign direct investment between asymmetric countries in a two stage dynamic game. It is not only that countries compete in taxes but also competition in terms of providing infrastructure which adds another dimension to this issue. Combes and Lafourcade (2001), in the context of France, show that more firms have come in due to a decrease in the transport costs on account of better infrastructural facilities when analyzed over a period of 20 years. Similar observations were made by Duranton and Puga (2001). Lastly, in a completely different set-up, Karlsson and Zhang (2001) incorporate how changes in education policy and human capital formation can affect the location of a multinational corporation.

Coming back to the focus area, the concept of tax competition creating an intense pressure on the governments to reduce their corporate tax rates is a part of a growing body of literature which has kind of taken off since the work by Wilson (1999). Detailed attempts based on empirical evidences are really hard to come by may be due to the difficulty faced in deciding on an appropriate measure of taxation and hence fixing up the rate. Apart from these, changes in definitions of tax base and the net impact on the incentives of MNCs to invest have also hindered the carrying out of such empirical exercises. However, in spite of the pervasive evidence about the increasing importance of multinational firms in the globalized economy and on their capacity to restructure the financial flows across divisions to reduce tax liability, the study of how to make use of corrective devices (especially, with a focus on non-tax revenue) in such a system in which countries compete for the profits of multinationals has not been studied so far. The major gap lies here as theoretical models elaborate the tax revenue part but, in general, tend to overlook the non-tax revenue portion in the Government's optimization problem.

In this background, this paper makes a preliminary attempt to re-interpret the results under a situation of tax competition for the profit of multinationals but the twist is that profit shifting is now costly and there is a chance of getting caught. Moreover, the government can extract a part of the MNCs profit through fines, which is a part of non-tax revenue, thereby showing that there can be a trade off between such tax and non-tax revenue. So to address this issue the author proposes a simple theoretical model which shows that given the similar administrative efficiency across countries, a higher probability of non-detection indicates that more 
profits will be declared in the lower tax country. It shows that even though a fall in the non-detection probability reduces tax revenue but it might raise the overall revenue collections of the government. So, the focus should not only be on tax revenue per se but on other forms of revenue collections also.

\section{Theoretical Framework - The Model}

There are two countries, $a$ and $b$, where the authors have considered inverse market demand curves given by,

$p_{a}=\gamma_{a}-\beta q_{a}$

$p_{b}=\gamma_{b}-\beta q_{b}$

Given, $\gamma_{1} \geq \gamma_{2}$

There are $n$ multinational firms and each of these $n$ homogeneous firms owns a branch in each country. These firms compete in a Cournot framework in each market. The intention of the firms is to move their profits where they are subject to lesser tax rates. The unit production costs, the cost to ship goods across countries have been normalized to zero. More precisely, letting $\pi_{i}{ }^{j}$ be the profit effectively generated by firm $j=1,2,3, \ldots \ldots, n$ in country $i=a, b$. To escape the tax liability, the actual profit generated is not reported. This means that the declared profit across the two countries should add up to total profit of the firm in the two countries. Following Hindriks et al. (2014), the constraint becomes $\pi_{a}{ }^{j}+\pi_{b}{ }^{j}=\tilde{\pi}_{a}{ }^{j}+\tilde{\pi}_{b}{ }^{j}$ for the $j^{\text {th }}$ firm across two countries, $a$ and $b . \tilde{\pi}_{i}^{j}$ denotes the amount of profit reported by the $j^{\text {th }}$ firm in the $i^{\text {th }}$ country.

The firms plan to conceal their true profits based on what taxes the governments in different countries charge. Concealing true profits attract a fine and if the firm gets caught the entire profit gets confiscated and the firm gets zero. The probability of non-detection is given by $d$ and we have assumed it to remain the same across the countries with the objective of simplification. Following Schindler and Schjelderup (2013), we have introduced concealment cost in a slightly different manner as : $2\left(\pi_{i}{ }^{j}-\tilde{\pi}_{i}{ }^{j}\right)^{2}$ for the $j^{\text {th }}$ firm in the $i^{\text {th }}$ country. Doing the concealment of profit counts for both the countries i.e. doing for one country implies that it is done for the other country also as the structure is the same. The government in country $i$ sets a source-based tax rate, $t_{i}$, on the profit reported within its tax-jurisdiction by the $n$ multinational firms, and its tax revenue is given by:

$R_{i}=t_{i}\left(\tilde{\pi}^{1}{ }_{i}+\tilde{\pi}^{2}{ }_{i}+\tilde{\pi}^{3}{ }_{i}+\ldots \ldots \tilde{\pi}^{n}{ }_{i}\right), i=a$ and $b$

The objective of the $j^{\text {th }}$ firm is to maximize its profit across the two countries given the tax rates set by the governments of the two countries.

\section{The Decision of the Firms - A Tax Competition Framework}

The objective of the $j^{\text {th }}$ firm,

$\max d\left(1-t_{a}\right) \tilde{\pi}_{a}^{j}+d\left(1-t_{b}\right) \tilde{\pi}_{b}^{j}-2\left(\pi_{a}^{j}-\tilde{\pi}_{a}^{j}\right)^{2}$

w.r.t $\left(q^{j}{ }_{a}, q^{j}{ }_{b}, \tilde{\pi}_{a}^{j}\right)$

s.t $\tilde{\pi}_{a}{ }^{j}+\tilde{\pi}_{b}{ }^{j}=p_{a}\left(q_{a}^{1}+q_{a}^{2} \ldots \ldots+q_{a}^{n}\right) q_{a}^{j}+p_{b}\left(q^{1}{ }_{b}+q^{2}{ }_{b} \ldots \ldots+q_{b}^{n}\right) q_{b}^{j}$

In this case, the number of variables reduces to three as $\tilde{\pi}_{b}{ }^{j}$ can be written in terms of the other three variables.

Rewriting the maximization problem after combining the constraint,

$d\left(1-t_{a}\right) \tilde{\pi}_{a}^{j}+d\left(1-t_{b}\right)\left[\left(\gamma_{a}-\beta\left(q_{a}^{1}+q_{a}^{2} \ldots \ldots+q_{a}^{n}\right)\right) q_{a}^{j}+\left(\gamma_{b}-\beta\left(q^{1}{ }_{b}+q^{2}{ }_{b} \ldots \ldots+\right.\right.\right.$

$\left.\left.\left.q_{b}^{n}\right)\right) q_{b}^{j}-\tilde{\pi}_{a}^{j}\right]-2\left(\pi_{a}^{j}-\tilde{\pi}_{a}^{j}\right)^{2}$

From the first-order conditions:

(i) $-d t_{a}+d t_{b}+4\left(\left\{\gamma_{a}-\beta\left[q_{a}^{1}+q_{a}^{2} \ldots \ldots+q_{a}^{n}\right]\right\} q_{a}^{j}{ }_{a}-\tilde{\pi}_{a}^{j}\right)=0$

or, $-d\left(\frac{t_{a}-t_{b}}{4}\right)+\left\{\gamma_{a}-\beta\left[q_{a}^{1}+q_{a}^{2} \ldots \ldots+q_{a}^{n}\right]\right\} q_{a}^{j}=\tilde{\pi}_{a}^{j}$

(ii) $\quad d\left(1-t_{b}\right)\left[\gamma_{a}-\beta\left(q_{a}^{1}+q_{a}^{2} \ldots \ldots+q_{a}^{n}\right)-2 \beta q_{a}^{j}\right]-4\left(\left\{\gamma_{a}-\beta\left[q_{a}^{1}+q_{a}^{2} \ldots \ldots+q_{a}^{n}\right]\right\} q_{a}^{j}-\right.$ $\left.\tilde{\pi}_{a}^{j}\right)\left[\gamma_{a}-2 \beta q_{a}^{j}-\beta\left(q_{a}^{1}+q_{a}^{2} \ldots \ldots+q_{a}^{n}\right)\right]=0$

Using (4) and (5) we get, 
$d\left(1-t_{b}\right)\left[\gamma_{a}-\beta\left(q_{a}^{1}+q_{a}^{2} \ldots \ldots+q_{a}^{n}\right)-2 \beta q_{a}^{j}\right]-d\left(t_{a}-t_{b}\right)\left[\gamma_{a}-2 \beta q_{a}^{j}-\beta\left(q_{a}^{1}+q_{a}^{2} \ldots \ldots+\right.\right.$ $\left.\left.q_{a}^{n}\right)\right]$

or, $d\left(1-t_{b}-t_{a}+t_{b}\right)\left[\gamma_{a}-\beta\left(q_{a}^{1}+q_{a}^{2} \ldots \ldots+q_{a}^{n}\right)-2 \beta q_{a}^{j}\right]=0, t_{a} \neq 1, d \neq 0$

or, $q_{a}^{j}=\frac{\gamma_{a}-\beta\left(q_{a}^{1}+q_{a}^{2} \ldots \ldots+q_{a}^{n}\right)}{2 \beta}$

Similarly, carrying out the first order condition in terms of $q^{j}{ }_{b}$, we have,

$q_{b}^{j}=\frac{\gamma_{b}-\beta\left(q_{b}^{1}+q_{b}^{2} \ldots \ldots+q_{b}^{n}\right)}{2 \beta}$

Analogously carrying out the maximization exercise for the $\mathrm{n}$ firms leads us to $n$ such conditions for the $n$ firms, i.e. $j=1,2,3 \ldots n$. It should be noted that in equation (6) and (7), the term within brackets include $(n-1)$ terms actually as $j^{\text {th }}$ firm is excluded.

At the Nash Equilibrium, $q_{a}^{1}=q_{a}^{2}=q_{a}^{j} \ldots \ldots=q_{a}^{n}=q_{a}^{*}$ and

$$
q^{1}{ }_{b}=q^{2}{ }_{b}=q^{j}{ }_{b} \ldots \ldots=q_{b}^{n}=q^{*}{ }_{b} .
$$

So solving the values from equation (6) and equation (7),

$q^{*}{ }_{a}=\frac{\gamma_{a}}{\beta(n+1)}, q^{*}{ }_{b}=\frac{\gamma_{b}}{\beta(n+1)}$

Putting back the values in equation (1) and equation (2), we get,

$p_{a}=\frac{\gamma_{a}}{(n+1)}, p_{b}=\frac{\gamma_{b}}{(n+1)}$

By putting back the equilibrium values in equation (4), the profits reported by $j^{\text {th }}$ firm in country $a$ and $b$ can be derived as follows,

$-d\left(\frac{t_{a}-t_{b}}{4}\right)+\left\{\gamma_{a}-\beta\left[\frac{n \gamma_{a}}{(n+1) \beta}\right]\right\} \frac{\gamma_{a}}{\beta(n+1)}=\tilde{\pi}_{a}^{j}$
$-d\left(\frac{t_{b}-t_{a}}{4}\right)+\left\{\gamma_{b}-\beta\left[\frac{n \gamma_{b}}{(n+1) \beta}\right]\right\} \frac{\gamma_{b}}{\beta(n+1)}=\tilde{\pi}_{b}{ }^{j}$

The total profit disclosed in country $a$ is as follows,

$\tilde{\pi}_{a}=n \tilde{\pi}_{a}{ }^{j}, j=1,2,3, \ldots n$

$\Rightarrow \tilde{\pi}_{a}=n\left[-d\left(\frac{t_{a}-t_{b}}{4}\right)+\left\{\gamma_{a}-\beta\left[\frac{n \gamma_{a}}{(n+1) \beta}\right]\right\} \frac{\gamma_{a}}{\beta(n+1)}\right]$

Analogously one can write it for the second country. Firstly, we move on to the first case of tax competition among the countries. The objective of the government is to choose the taxes in such a way that global corporations get attracted to locate their business in the country having the lower tax rate. The entire thing happens in a setting of detection of concealment of true profits. Starting off with tax competition, the government in country $a$ collects tax revenue given by,

$R_{a}=t_{a}\left(\tilde{\pi}_{a}^{1}+\tilde{\pi}_{a}^{2}+\tilde{\pi}_{a}^{3}+\ldots \ldots \tilde{\pi}_{a}^{n}\right) \ldots \ldots \ldots(11)$ and similarly,

$R_{b}=t_{b}\left(\tilde{\pi}_{b}^{1}+\tilde{\pi}_{b}^{2}+\tilde{\pi}^{3}{ }_{b}+\ldots \ldots \tilde{\pi}_{b}^{n}\right)$

The first order conditions from the revenue maximization of the government yields,

$\frac{\partial R_{a}}{\partial t_{a}}=0 \Rightarrow n\left[\left\{\gamma_{a}-\beta\left[\frac{n \gamma_{a}}{(n+1) \beta}\right]\right\} \frac{\gamma_{a}}{\beta(n+1)}\right]-n d\left[\frac{t_{a}}{2}-\frac{t_{b}}{4}\right]=0$

$\frac{\partial R_{b}}{\partial t_{b}}=0 \Rightarrow n\left[\left\{\gamma_{b}-\beta\left[\frac{n \gamma_{b}}{(n+1) \beta}\right]\right\} \frac{\gamma_{b}}{\beta(n+1)}\right]-n d\left[\frac{t_{b}}{2}-\frac{t_{a}}{4}\right]=0$

For comparison of the tax rates across countries, following Hindriks et al. (2014) we normalize $\gamma_{b}$ and $\gamma_{a}$ as, 
$\gamma_{a}=\frac{(n+1)}{n} \sqrt{\beta(1+\varepsilon)}, \gamma_{b}=\frac{(n+1)}{n} \sqrt{\beta(1-\varepsilon)}$

Invoking equation (15) in equation (13) and (14),

$\left[\frac{t_{a}}{2}-\frac{t_{b}}{4}\right] n d=\frac{1+\varepsilon}{n} \ldots \ldots \ldots$

$\left[\frac{t_{b}}{2}-\frac{t_{a}}{4}\right] n d=\frac{1-\varepsilon}{n}$

Solving equation (16) and (17) simultaneously,

$t_{a}=\frac{4(3+\varepsilon)}{3 n^{2} d} ; t_{b}=\frac{4(3-\varepsilon)}{3 n^{2} d} \ldots \ldots \ldots$

Both $t_{a}$ and $t_{b}$ are $<1$ as $n>2 \sqrt{\frac{1}{d}\left(1+\frac{\varepsilon}{3}\right)}$

\section{Results}

Proposition 1: At the Nash equilibrium, there is under-taxation and the joint tax revenue is sub-optimal. If the probability of non-detection falls i.e. actually probability of detection rises then profit shifting becomes more costly and Nash equilibrium taxes will increase along with joint tax revenue.

First, under tax cooperation, the objective function is different,

$\max \left(t_{a}, t_{b}\right) t_{a}\left(\tilde{\pi}_{a}^{1}+\tilde{\pi}_{a}^{2}+\tilde{\pi}_{a}^{3}+\ldots \tilde{\pi}_{a}^{n}\right)+t_{b}\left(\tilde{\pi}_{b}^{1}+\tilde{\pi}_{b}^{2}+\tilde{\pi}_{b}^{3}+\ldots \tilde{\pi}_{b}^{n}\right)$

Under tax cooperation $t_{a}=t_{b}$ and since the maximum value that $\mathrm{t}$ can take is 1 so the maximum joint revenue turns out to be 1 . The result is feasible given the condition imposed on $\varepsilon$ and that tax rates $\in[0,1]$.

Proposition 2: With the non-detection probability, $d$, in place, there is a chance that the firm might not get caught at all or it might happen that the entire profit gets confiscated. So, a higher value of d means that more profits will be declared in the lower tax country. If $d \rightarrow 0$ (not zero as we have assumed) then more profits will be declared in the higher tax country on account of its larger tax base and $d \rightarrow 1$ means declared profit will be more in case of the lower tax country as expected.

Now, we will check out the impact of probability of non-detection on tax revenue. The value of optimum tax revenue in both the countries can be found out by using the optimum values in equation (9), (10) and (18).

$R_{a}=t_{a}\left(\tilde{\pi}_{a}^{1}+\tilde{\pi}_{a}^{2}+\tilde{\pi}_{a}^{3}+\ldots \ldots \tilde{\pi}_{a}^{n}\right)$

$R_{a}=\frac{4(3+\varepsilon) n\left[-d\left(\frac{t_{a}-t_{b}}{4}\right)+\left\{\gamma_{a}-\beta\left[\frac{n \gamma_{a}}{(n+1) \beta}\right]\right\} \frac{\gamma_{a}}{\beta(n+1)}\right]}{3 n^{2} d}$

Normalizing the values of $\gamma_{a}$ and $\gamma_{b}$ using equation (15),

$R_{a}=-\frac{(3+\varepsilon)}{3 n}\left(t_{a}-t_{b}\right)+\frac{4(3+\varepsilon)\left[\frac{n+1}{n^{2}}(1+\varepsilon)-\frac{n+1}{n} \beta(1+\varepsilon)\right]}{3 n d} \ldots \ldots \ldots$

$\frac{\partial R_{a}}{\partial d}=-\frac{4(3+\varepsilon)\left[\frac{n+1}{n^{2}}(1+\varepsilon)-\frac{n+1}{n} \beta(1+\varepsilon)\right]}{3 n d^{2}}>0$ given $\beta>\frac{1}{n} ;$

As $d$ rises $R_{a}$ rises. Similarly, doing for country b, we have

$$
\begin{aligned}
& R_{b}=-\frac{(3-\varepsilon)}{3 n}\left(t_{b}-t_{a}\right)+\frac{4(3-\varepsilon)\left[\frac{n+1}{n^{2}}(1-\varepsilon)-\frac{n+1}{n} \beta(1-\varepsilon)\right]}{3 n d} \\
& \frac{\partial R_{b}}{\partial d}=-\frac{4(3-\varepsilon)\left[\frac{n+1}{n^{2}}(1-\varepsilon)-\frac{n+1}{n} \beta(1-\varepsilon)\right]}{3 n d^{2}}>0 ;
\end{aligned}
$$

\footnotetext{
${ }^{2} \boldsymbol{\varepsilon}$ denotes the heterogeneity between the two countries in terms of fiscal revenue, market size, etc, i.e. $\mathbf{0} \leq \boldsymbol{\varepsilon} \leq \mathbf{1}$
} 
Proposition 3: A rise in the probability of non-detection implies that there is a lesser chance of getting caught which in turn means that given the normal tax rates, tax revenue rises irrespective of which country we are talking about. Alternatively, this can be intuitively explained through the fact that the moment $d$ falls, the profit of more firms will be confiscated i.e. those firms will be left with zero profit, so on zero profit tax cannot be imposed. As a result tax revenue falls.

Here, we are actually talking about tax revenue per se but the confiscated income of those firms who gets caught also come to the government treasury. The moment that income comes into the picture and explicitly gets modeled then looking into the outcome will become more interesting.

We remodel the total revenue collected as tax revenue plus the confiscated income of those firms who have been detected of concealing true profits.

$$
\begin{aligned}
& R_{a}=\left(d t_{a}+1-d\right)\left(\tilde{\pi}^{1}{ }_{a}+\tilde{\pi}^{2}{ }_{a}+\tilde{\pi}^{3}{ }_{a}+\ldots \ldots \tilde{\pi}_{a}^{n}\right) \ldots \ldots \ldots \\
& R_{b}=\left(d t_{b}+1-d\right)\left(\tilde{\pi}_{b}^{1}+\tilde{\pi}_{b}{ }_{b}+\tilde{\pi}_{b}^{3}+\ldots \ldots \tilde{\pi}_{b}{ }_{b}\right) \ldots \ldots \ldots
\end{aligned}
$$

So, carrying out the same exercise of looking into what happens to the revenue collections of the government under a situation of a rise in probability of non-detection.

$R_{a}=n\left[-d\left(\frac{t_{a}-t_{b}}{4}\right)+\left\{\frac{n+1}{n^{2}}(1+\varepsilon)-\frac{n+1}{n} \beta(1+\varepsilon)\right\}\right]\left[\frac{4(3+\varepsilon)}{3 n^{2}}+1-d\right]$
$\frac{\partial R_{a}}{\partial d}=2 d n\left(\frac{t_{a}-t_{b}}{4}\right)-n\left(\frac{t_{a}-t_{b}}{4}\right)\left[1+\frac{4(3+\varepsilon)}{3 n^{2}}\right]-\left\{\frac{n+1}{n^{2}}(1+\varepsilon)-\frac{n+1}{n} \beta(1+\varepsilon)\right\}$

Analogously, for country b,

$\left.\frac{\partial R_{b}}{\partial d}=2 d n \frac{t_{b}-t_{a}}{4}\right)-n\left(\frac{t_{b}-t_{a}}{4}\right)\left[1+\frac{4(3-\varepsilon)}{3 n^{2}}\right]-\left\{\frac{n+1}{n^{2}}(1-\varepsilon)-\frac{n+1}{n} \beta(1-\varepsilon)\right\}$

Given, the condition, $\beta>\frac{1}{n}$, The signs of $\frac{\partial R_{a}}{\partial d}$ and $\frac{\partial R_{b}}{\partial d}$ will depend on the strength of the negative and the positive effects. The first term is positive, the last term is negative but with a negative sign before, it becomes positive and the middle term is positive but with a negative sign before, it becomes negative.

Proposition 4: The overall change in revenue collections will get determined not only through tax revenue collection but also through confiscated profits. So, a falling $d$ means, a fall in the tax revenue but more of confiscated profits. At this point, the strength of these two effects will determine whether a fall in d can actually raise the revenue collections of the government. Also, the government should focus not only on taxes but also on other forms of revenue collection i.e. fines, confiscation of profit, etc.

\section{Concluding Remarks}

For many years tax policy in countries like USA, UK, Germany and France exempted foreign source-income fully or almost fully from domestic taxation. In the context of corporate taxation, it is indeed striking to know that there is a significant rise in the number of countries exempting foreign-source income. According to Devereux et al. (2008), out of 37 high-income countries, 19 had an exemption system in 1998, rising to 27 in 2008. A number beyond one's imagination. Realistically, one can relate this situation to the case of South Korea in the recent years. South Korea's tax revenue as a percentage of GDP (given the level of GDP remaining roughly the same during the period 2011-16 at constant PPP\$) shows a declining trend whereas fines or penalties as percentage of GDP during the same period at constant PPP\$ shows a rising trend of a much higher magnitude (Refer to Figure 1). This model can provide an argument, as already explained in Proposition 4 on the existence of such a trade off between fines or penalties and corporate tax revenue collections. The primary objective of this paper is to throw light on the fact that even when tax rates are lowered to attract MNC's, government's tax revenue collection falls but through other forms of non-tax revenue like fines or penalties, the government can make up for it and maintain the overall revenue collections. 


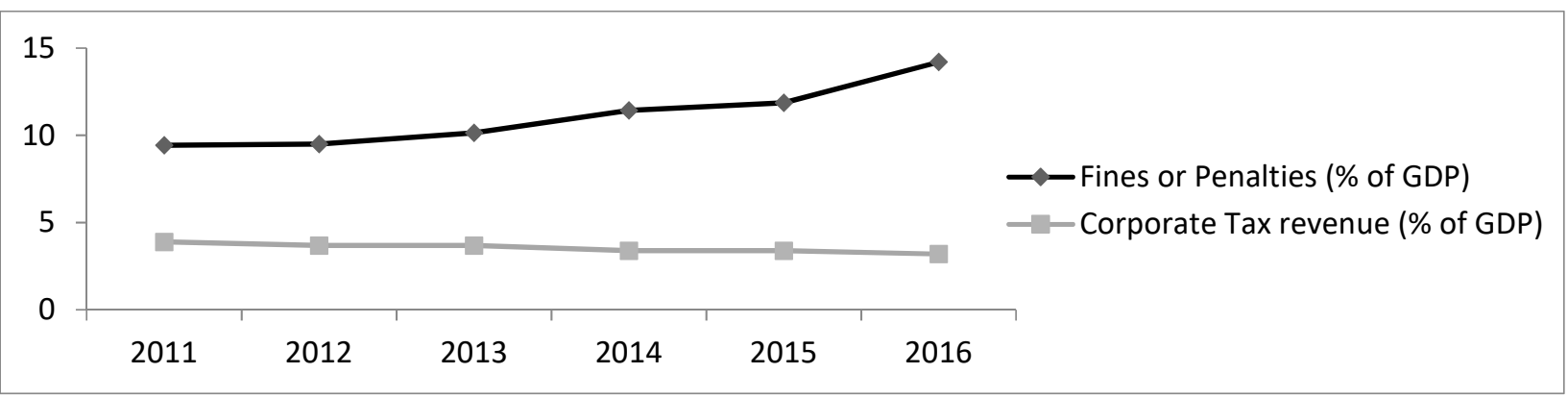

Figure 1. Corporate Tax Revenue vs. Fines or Penalties as a percentage of GDP

Source: Data as retrieved from OECD database.

In this context, the paper has highlighted that how in a $n$ firm and two country framework there is undertaxation in equilibrium and combined tax revenue is sub-optimal in the presence of penalty imposition for concealment of profits when two countries are competing for the profits of MNCs. A higher chance of nondetection implies that higher will be the profits declared in the low tax jurisdiction, vice versa. The attentiongrabbing observation has been the movement of tax revenue in line with the probability of non-detection. The more the chance of not getting caught higher will be the tax revenue collected, vice versa. Does it mean that a higher chance of detection brings less revenue to the government treasury? As we have shown, a higher chance of detection means lower tax revenue collection but other forms of collections i.e. fines, penalty, etc. needs to be incorporated to get a holistic view of the revenue collections of the government. Thus, depending on the size of the market and the number of firms a higher chance of detection can bring in increased revenue (overall). Furthermore, the chance of non-detection becomes crucial in determining the extent of tax competition. The soundness of this model in a setting of diverse administrative capabilities i.e. presence of different detection probabilities is an exercise worth exploring and has been left for further research.

\section{References}

1. Baldwin, R. E., \& Krugman, P. (2004). Agglomeration, integration and tax harmonisation. European Economic Review, 48(1), 1-23.

2. Besley, T., \& Seabright, P. (1999). The effects and policy implications of state aids to industry: an economic analysis. Economic Policy, 14(28), 14-53.

3. Combes, P. P., \& Lafourcade, M. (2001). Transport Cost Decline and Regional Inequalities: Evidence from France (No. 2894). CEPR Discussion Papers.

4. Duranton, G., \& Puga, D. (2001). Nursery cities: Urban diversity, process innovation, and the life cycle of products. American Economic Review, 91(5), 1454-1477.

5. Devereux, M. P., Lockwood, B., \& Redoano, M. (2008). Do countries compete over corporate tax rates?. Journal of Public Economics, 92(5), 1210-1235.

6. Fumagalli, C. (2003). On the welfare effects of competition for foreign direct investments. European Economic Review, 47(6), 963-983.

7. Haufler, A., \& Wooton, I. (1999). Country size and tax competition for foreign direct investment. Journal of Public Economics, 71(1), 121-139.

8. Haufler, A., \& Lülfesmann, C. (2015). Reforming an asymmetric union : On the virtues of dual tier capital taxation. Journal of Public Economics, 125, 116-127.

9. Haufler, A., \& Schjelderup, G. (2000). Corporate tax systems and cross country profit shifting. Oxford Economic Papers, 52(2), 306-325.

10. Hindriks, J., Perlata, S., \& Weber, S. (2014). Local taxation of global corporation : a simple solution. Annals of Economics and Statistics/Annales d'Économie et de Statistique, (113-114), 37-65.

11. Karlsson, C., \& Zhang, W. B. (2001). The role of universities in regional development. Endogenous human capital and growth in a two-region model. The Annals of Regional Science, 35(2), 179-197.

12. Kind, H. J., Midelfart, K. H., \& Schjelderup, G. (2003). Trade and Multinationals : the effect of economic integration on taxation and tax revenue.

13. Mansori, K. S., \& Weichenrieder, A. J. (2001). Tax competition and transfer pricing disputes. Finanz Archiv : Public Finance Analysis, 58(1), 1-11.

14. Peralta, S., \& Van Ypersele, T. (2006). Coordination of capital taxation among asymmetric countries. Regional Science and Urban Economics, 36(6), 708-726.

15. Raimondos-Møller, P., \& Scharf, K. (2002). Transfer pricing rules and competing governments. Oxford Economic Papers, 54(2), 230-246. 
16. Riedel, N., \& Runkel, M. (2007). Company tax reform with a water's edge. Journal of Public Economics, 91(7), 1533-1554.

17. Schindler, D., \& Schjelderup, G. (2013, June). Profit Shifting and Corporate Profit Tax Evasion. In 8th Norwegian-German Seminar on Public Economies.

18. Vandenbussche, H., Crabbé, K., \& Janssen, B. (2005). Is there regional tax competition? Firm level evidence for Belgium. De economist, 153(3), 257-276.

19. Wilson, J. D. (1999). Theories of tax competition. National Tax Journal, 52(2), 269-304. 